\title{
EFFECT OF LOWERING THE DOSE OF MISOPROSTOL FOR SECOND TRIMESTER TERMINATION OF PREGNANCY ALONG WITH MIFEPRISTONE
}

\author{
Mohita Singal1, Vinita Gupta², Shikha Pasrija³, Nivedita Sarda ${ }^{4}$
}

1 Senior Resident, Department of Obstetrics and Gynaecology, Dr. Baba Saheb Ambedkar Hospital and Medical College, Delhi.

¿Senior, Department of Obstetrics and Gynaecology, Dr. Baba Saheb Ambedkar Hospital and Medical College, Delhi.

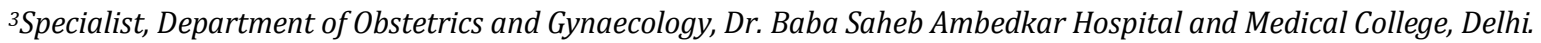

${ }^{4}$ Professor, Department of Obstetrics and Gynaecology, Dr. Baba Saheb Ambedkar Hospital and Medical College, Delhi.

\begin{abstract}
BACKGROUND
In India, second trimester termination is reportedly performed in about 11 - 14\% of women. However, abortion is grossly underreported in the official data. A large number of termination of pregnancies is done by unaccredited centres due to various reasons and thus it is extremely important to ensure the safety of the regimen when used in a low-resource setting. So, we conducted a study to determine if lowering the dose of misoprostol significantly compromises the efficacy of second trimester abortion regimens.

Aims and Objectives- To study if decreasing the dose of misoprostol used for second trimester termination of pregnancy significantly alters the efficacy of the regimen and also if it is more acceptable in terms of complications and side effects.
\end{abstract}

\section{MATERIALS AND METHODS}

100 women seeking termination of pregnancy between 12 - 20 weeks of gestation were randomised into two equal groups using computerised random number tables. Women were given Tab. Mifepristone $200 \mathrm{mg}$ orally followed by 36 hours and later by Tab. Misoprostol $400 \mathrm{mcg}$ or $200 \mathrm{mcg}$ vaginally 3 hourly for a maximum of 5 doses in Group R1 and R2 respectively. Comparison was done using stringent and non-stringent criteria depending on whether a check curettage was required or not. Statistical analysis was done using Chi-square/ Fisher's exact test for qualitative variables and student's ' $t$ ' test for quantitative variables.

Settings and Design- A prospective randomised comparative study at a District Hospital.

\section{RESULTS}

The two groups were comparable in terms of age, parity and gravidity. Success rate at the end of 72 hours was $82 \%$ and $88 \%$ in Group R1 and R2 respectively using stringent criteria and $98 \%$ and $96 \%$ using non-stringent criteria. Mean induction abortion interval was 42.89 ( \pm 9.66$)$ in R1 and $43.09( \pm 8.62)$ in R2 using stringent criteria. We found that regimens are comparable in terms of safety, success, induction-abortion interval and side effects.

\section{CONCLUSION}

Reduction in misoprostol dose does not alter the efficacy of the mifepristone and misoprostol regimen significantly.

\section{KEYWORDS}

Termination of Pregnancy, Second Trimester Abortion, Misoprostol, Mifepristone.

HOW TO CITE THIS ARTICLE: Singal M, Gupta V, Pasrija S, et al. Effect of lowering the dose of misoprostol for second trimester termination of pregnancy along with mifepristone. J. Evolution Med. Dent. Sci. 2018;7(17):2134-2137, DOI: $10.14260 /$ jemds/2018/477

\section{BACKGROUND}

Pregnancy termination is relatively more effective, simpler and safer in first trimester which comprises about $85 \%$ of all abortion cases in India. ${ }^{1}$ Second trimester abortion however is an important medico-social problem, as they are responsible for most of the abortion related complications and ideal effective treatment is still a matter of concern. ${ }^{1}$ In India ignorance and inability to take early decision regarding abortion, inaccessibility of services and provider as well as paucity of organised abortion facilities compels a large number of women to seek termination of pregnancy in second trimester. A large number of termination of pregnancies is done by unaccredited centres due to various

'Financial or Other Competing Interest': None.

Submission 24-02-2018, Peer Review 05-04-2018,

Acceptance 12-04-2018, Published 23-04-2018.

Corresponding Author:

Dr. Shikha Pasrija,

CA-16, Tagore Garden,

New Delhi-110027, India.

E-mail: shikhapasrija@gmail.com

DOI: $10.14260 /$ jemds $/ 2018 / 477$

\section{(c) (i) $\circledast$}

reasons and thus it is extremely important to ensure the safety of the regimen when used in a low-resource setting. So we conducted a study to determine if lowering the dose of misoprostol significantly compromises the efficacy of second trimester abortion regimens. This study is a small step in the same direction comparing two different doses of misoprostol when combined with fixed dose of mifepristone to improve efficacy without compromising safety.

\section{MATERIALS AND METHODS}

The prospective randomised comparative study was conducted in a district hospital at New Delhi, India. The hospital scientific and ethical committee approval was sought before the study.

Based on the past 5-year of hospital census, number of women reporting for second trimester abortion was 836 (considered as population). Assuming confidence level of $95 \%$ and confidence interval of $10 \%$. Calculated sample size was 86. So we took 100 patients and divided into two Groups R1 and R2 using computerised random number tables. All women seeking termination of pregnancy between 12 - 20 weeks period of gestation were screened for the inclusion and 
exclusion criteria and those fulfilling the criteria were included into the study. Inclusion criteria were women with singleton pregnancy and willingness to participate in the study. Reasons for termination were either intrauterine death or congenital anomaly incompatible with life or on basis of humanitarian, social or medical grounds as per the Medical Termination of Pregnancy Act of the country. ${ }^{2}$ Exclusion criteria were previously more than one caesarean section, severe hypertension (blood pressure $\geq 160 / 100 \mathrm{mmHg}$ ), known intolerance or allergy to mifepristone or misoprostol, contraindications to the administration of mifepristone (chronic systemic corticosteroid therapy, adrenal insufficiency or misoprostol- glaucoma, sickle cell anaemia, poorly controlled seizures, known prostaglandin allergy, severe asthma, arrhythmias, cardiac failure), coagulopathy, multiple pregnancies and haemoglobin $<8 \mathrm{~g} \%$.

After informed consent, women were randomised by computer generated randomisation tables into two groups (R1 and R2). Women in Group R1 were given Tab. Mifepristone $200 \mathrm{mg}$ orally followed by 36 hours and later Tab. misoprostol $200 \mathrm{mcg}$ vaginally 3 hourly maximum 5 doses. Women in Group R2 were given Tab. Mifepristone 200 mg orally followed by 36 hours and later Tab. misoprostol 400 mcg vaginally 3 hourly maximum 5 doses. Time of expulsion of foetus and placenta were recorded.

Completeness of abortion at 72 hours was taken as successful regimen. Failure was defined as need of recourse to use of any other pharmacological/ surgical intervention for completion of termination. Outcomes were also calculated using less stringent criteria for determining the successful cases by considering the cases of incomplete abortion, which required immediate evacuation of retained products of conception at the time of expulsion of foetus and placenta due to excessive bleeding or tissue hanging out of the cervix to be a success. Statistical analysis was done using Chisquare/Fisher's exact test for qualitative variables and student's ' $t$ ' test for quantitative variables.

\section{RESULTS}

The age of the women enrolled in the study ranged from 18 39 years with mean age in the Group R1 being $25.12 \pm 4.11$ years and in Group R2 was $25.18 \pm 3.75$ years. The mean parity in Groups R1 and R2 was $1.16 \pm 1.36$ and $0.9 \pm 0.97$ respectively. The mean number of previous abortions in Group R1 and R2 were $0.3 \pm 0.65$ and $0.42 \pm 0.86$ respectively. The mean parity was $1.02 \pm 1.25$ in Group R1 and $0.82 \pm 0.92$ in Group R2. The mean gestational age of patients in two groups was $17.08 \pm 2.60$ years and $16.95 \pm$ 2.46 years respectively with ' $p$ ' value of 0.40 . The differences in these parameters amongst the two groups were statistically insignificant. Thus, the two groups were comparable in terms of age, parity, gravidity and number of previous abortions, number of living children and period of gestation and reason for termination of pregnancy (Table 1).

The most common indication for termination was congenital malformations followed by intrauterine death of foetus in both groups. Other indications were limiting family size, multi-drug resistant tuberculosis. Using stringent criteria that is no intervention needed at any time, the number of women with successful outcome at the end of 48 hours were 32 that is $78.04 \%$ in Group R1 and 33 (75\%) in
Group R2. Successful outcome at the end of 72 hours was observed in 41 (82\%) and 44 (88\%) women in Groups R1 and R2 respectively. The difference was statistically nonsignificant at both 48 and 72 hours (Table 2). The cumulative success rates in two groups is depicted in Figure 1.

When non-stringent criteria was used to assess the success rates of two regimens, the success rates were $78 \%$ (39) in Group R1 and 74\% (37) women in Group R2 at 48 hours. The success was found to be $98 \%$ (49) women and $96 \%$ (48) women at 72 hours in Group R1 and R2 respectively. The difference was found to be statistically nonsignificant at both 48 and 72 hours (Table 3).

Check curettage was done if some retained products of conception or placental bits were thought to be left after examining the expelled products or if patients were found to be bleeding more than average. In Group R1 8 women out of 49 and in Group R2 4 out of 48 women required check curettage. The ' $p$ ' value calculated was 0.75 , which was not statistically significant.

There were 9 failures (aborting after 72 hours) in Group R1 as compared to 6 failures in Group R2, but this difference also did not reach statistically significant levels. There was $1(2 \%)$ woman in Group R1 and 2 (4\%) women in Group R2 who did not respond to the regimens used and some other method or repeat regimen had to be used to induce abortion.

The mean induction abortion interval starting from the mifepristone dosage was 42.89 hrs. $( \pm 9.66)$ in Group R1 and 43.09 hrs. ( \pm 8.62$)$ in Group R2 using stringent criteria. The pvalue was calculated as 0.46 , which is non-significant. Using the less stringent criteria the interval was $42.20 \mathrm{hrs}$. $( \pm 0.84)$ in Group R1 and 41.58 hrs. ( \pm 10.90) in Group R2. The 'p' value here was 0.39 , which again showed insignificant difference (Table 4).

The difference in mean induction abortion interval from the start of misoprostol administration using less stringent criteria was non-significant as shown by the 'p' value of 0.39 . The mean time till abortion in Group R1 was 8.46 hours and in Group R2 was 8.82 hours.

Using stringent criteria, the mean time for abortion after starting mifepristone in primigravida was $48.58 \mathrm{hrs}$. and 42.02 hrs. in Groups R1 and R2 respectively. The corresponding figures in multigravida were 39.94 hours and 43.75 hours in Groups R1 and R2 respectively. Analysis showed a statistically non-significant ' $p$ ' values (Table 5).

Using less stringent criteria, the mean abortion interval in primigravida was 47.40 hrs. and 40.05 hrs. in Groups R1 and $\mathrm{R} 2$ respectively. The corresponding figures in multigravida were $39.46 \mathrm{hrs}$. and $42.50 \mathrm{hrs}$. in Groups R1 and R2 respectively. This was statistically non-significant (Table 6).

The side effects reported were nausea, vomiting and fever. In Group R1 two (4\%) women had nausea and vomiting, whereas no woman complained of these in Group R2. Fever was reported in four (8\%) women in Group R1 and three (6\%) women in Group R2. Postpartum psychosis developed in one patient in Group R1 and none in Group R2. There were 5 patients with previous caesareans and no additional complications were noted, though number of scarred uterus cases was too small to reach any conclusion. The ' $p$ ' value calculated for the complications was not statistically significant (Table 7). 


\begin{tabular}{|c|c|c|c|}
\hline & $\begin{array}{c}\text { Group R1 } \\
\text { Mean } \pm \text { SD }\end{array}$ & $\begin{array}{c}\text { Group R2 } \\
\text { Mean } \pm \text { SD }\end{array}$ & P value \\
\hline Age & $25.12 \pm 4.11$ & $25.18 \pm 3.75$ & 0.47 \\
\hline Parity & $01.16 \pm 1.36$ & $00.90 \pm 0.97$ & 0.14 \\
\hline $\begin{array}{c}\text { No. of } \\
\text { Previous } \\
\text { Abortions }\end{array}$ & $00.30 \pm 0.65$ & $00.42 \pm 0.86$ & 0.22 \\
\hline $\begin{array}{c}\text { No of Living } \\
\text { Children }\end{array}$ & $01.02 \pm 1.25$ & $00.82 \pm 0.92$ & 0.18 \\
\hline $\begin{array}{c}\text { Period of } \\
\text { Gestation }\end{array}$ & $17.08 \pm 2.60$ & $16.95 \pm 2.46$ & 0.40 \\
\hline \multicolumn{3}{|c|}{ Table 1. Demographic Distribution } \\
\hline
\end{tabular}

\begin{tabular}{|c|c|c|}
\hline & \multicolumn{2}{|c|}{ Successful Outcome } \\
\hline & At 48 Hours N (\%) & At 72 Hours N (\%) \\
\hline R1 & $32(78 \%)$ & $41(82 \%)$ \\
\hline R2 & $33(75 \%)$ & $44(88 \%)$ \\
\hline \multicolumn{2}{|c|}{$\mathrm{p}=0.90$} & $\mathrm{p}=0.75$ \\
\hline \multicolumn{2}{|c|}{ Table 2. Successful Outcome at 48 and 72 hours using } \\
Stringent Criteria \\
\hline
\end{tabular}

\begin{tabular}{|c|c|c|}
\hline & $\begin{array}{c}\text { Successful Outcome using Less Stringent } \\
\text { Criteria }\end{array}$ \\
\hline & At 48 Hours N (\%) & At 72 Hours N (\%) \\
\hline $\mathrm{R} 1$ & $39(78 \%)$ & $49(98 \%)$ \\
\hline $\mathrm{R} 2$ & $37(74 \%)$ & $48(96 \%)$ \\
\hline \multicolumn{2}{|c|}{$\mathrm{p}=0.82$} & $\mathrm{p}=0.90$ \\
\hline \multicolumn{2}{|c|}{ Table 3. Successful Outcome at 48 and 72 hours using } \\
Less Stringent Criteria
\end{tabular}

\begin{tabular}{|c|c|c|}
\hline & $\begin{array}{c}\text { Mean Induction Abortion Interval in Hours } \\
\text { Mean } \pm \text { SD }\end{array}$ \\
\hline & $\begin{array}{c}\text { Using Stringent } \\
\text { Criteria }\end{array}$ & $\begin{array}{c}\text { Using Less Stringent } \\
\text { Criteria }\end{array}$ \\
\hline $\mathrm{R} 1$ & $42.89 \pm 9.66$ & $42.20 \pm 0.84$ \\
\hline $\mathrm{R} 2$ & $43.09 \pm 8.62$ & $41.58 \pm 10.90$ \\
\hline \multicolumn{3}{|c|}{ Table 4. Mean Induction Abortion Interval } \\
\hline \multicolumn{2}{|c|}{}
\end{tabular}

\begin{tabular}{|c|c|c|}
\hline & \multicolumn{2}{|c|}{ Mean Induction Abortion Interval in Hours } \\
\hline & Primigravida & Multigravida \\
\hline $\mathrm{R} 1$ & $48.58 \pm 7.54$ & $39.94 \pm 9.42$ \\
\hline $\mathrm{R} 2$ & $42.02 \pm 8.52$ & $43.75 \pm 8.77$ \\
\hline \multicolumn{2}{|c|}{$\mathrm{p}=0.49$} & $\mathrm{p}=0.67$ \\
\hline \multicolumn{2}{|c|}{ Table 5. Mean Induction Abortion Interval as per } \\
Gravidity using Stringent Criteria
\end{tabular}

\begin{tabular}{|c|c|c|}
\hline & \multicolumn{2}{|c|}{ Mean Induction Abortion Interval In Hours } \\
\hline & Primigravida & Multigravida \\
\hline $\mathrm{R} 1$ & $47.40 \pm 7.47$ & $39.96 \pm 9.95$ \\
\hline $\mathrm{R} 2$ & $40.05 \pm 11.44$ & $42.50 \pm 10.44$ \\
\hline \multicolumn{2}{|c|}{$\mathrm{p}=0.43$} & $\mathrm{p}=0.73$ \\
\hline \multicolumn{2}{|c|}{$\begin{array}{c}\text { Table 6. Mean Induction Abortion Interval as per } \\
\text { Gravidity using Less Stringent Criteria }\end{array}$} \\
\hline
\end{tabular}

\begin{tabular}{|c|c|c|c|c|c|}
\hline \multirow{2}{*}{$\begin{array}{c}\text { Side Effects/ } \\
\text { Complications }\end{array}$} & \multicolumn{2}{|c|}{ Group R1 } & \multicolumn{2}{c|}{ Group R2 } & \multirow{2}{*}{ P value } \\
\cline { 2 - 6 } & No. & $\mathbf{\%}$ & No. & $\mathbf{\%}$ & \\
\hline Nausea & 2 & 4 & 0 & 0 & 0.15 \\
\hline Vomiting & 2 & 4 & 0 & 0 & 0.15 \\
\hline Diarrhoea & 0 & 0 & 0 & 0 & 1.00 \\
\hline Fever & 4 & 8 & 3 & 6 & 0.70 \\
\hline $\begin{array}{c}\text { Excessive } \\
\text { Bleeding }\end{array}$ & 0 & 0 & 0 & 0 & 1.00 \\
\hline Others & 1 & 2 & 0 & 0 & 0.32 \\
\hline Total & 9 & & 3 & & \\
\hline \multicolumn{7}{|l|}{ Table 7. Side Effects and Complications } \\
\hline
\end{tabular}

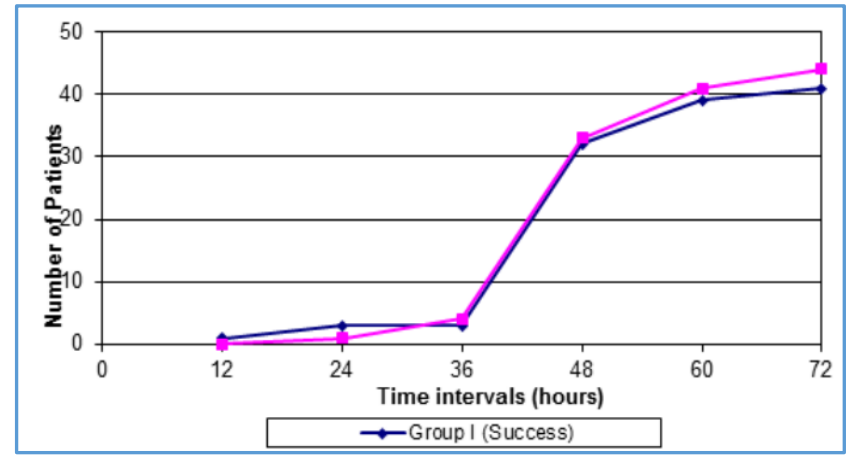

Figure 1. Cumulative Successful Outcome at Time Intervals

\section{DISCUSSION}

The combination of mifepristone and misoprostol has been found to be an effective method of termination of pregnancy in second trimester. The optimisation of the mifepristone and misoprostol regimens is still on to decrease the economic burden on hospitals and to improve efficacy, acceptability and compliance with minimal effects to women's health.

A 2011 Cochrane ${ }^{3}$ review compared different methods of second trimester medical termination of pregnancy for their efficacy and side effects and concluded that low doses of misoprostol appear to be associated with fewer side effects, while moderate doses appear to be more efficient in completing abortion. It also found that the induction to abortion interval with 3-hourly vaginal administration of prostaglandins is shorter than 6-hourly administration without an increase in side effects.

In our study, we found no statistically significant difference in efficacy by lowering the dose of misoprostol from $400 \mu \mathrm{g}$ to $200 \mu \mathrm{g}$, keeping the interval of administration fixed at $3 \mathrm{hrs}$. Success rates were $88 \%$ and $82 \%$ with $400 \mu \mathrm{g}$ and $200 \mu \mathrm{g}$ respectively at $72 \mathrm{hrs}$. using stringent criteria. Success rates reached $96 \%$ and $98 \%$ with $400 \mu \mathrm{g}$ and $200 \mu \mathrm{g}$ respectively at $72 \mathrm{hrs}$. using less stringent criteria.

We also did not find any significant difference in the side effects between the two dose regimens. Side effects were nausea ( $4 \%$ vs. $0 \%$ ), fever ( $8 \%$ vs. $4 \%$ ) and vomiting ( $4 \%$ vs. $0 \%$ ) and were in fact lower in Group R2 in absolute numbers despite higher dose.

The latest recommendation by $\mathrm{ACOG}^{4}, \mathrm{RCOG}^{5}$ and $\mathrm{WHO}^{6}$ recommends Loading Dose (LD) of $800 \mu \mathrm{g}$ misoprostol followed by $400 \mu \mathrm{g} 3$ hourly. Varying success rates have been reported upto $100 \%$.

In present study, without using any LD we compared misoprostol dose of $400 \mu \mathrm{g}$ and $200 \mu \mathrm{g} 3$ hourly max 5 doses and found success rates upto $98 \%$ and $96 \%$.

Pongsatha $^{7}$ et al compared a vaginal misoprostol LD regimen (600 $\mathrm{mcg}$, then $400 \mathrm{mcg} 6$ hourly) with a nonloading dose regimen ( 400 mcg 6 hourly) in 157 women and found both equally effective with adverse drug effects associated more with loading dose regimens.

Similarly, a study without any LD by Koh et al ${ }^{8}$ found $400 \mu \mathrm{g}$ and $200 \mu \mathrm{g}$ misoprostol 4 hourly regimens very effective with a success rates of $92.5 \%$ and $70.3 \%(p=0.017)$ with significantly less side effects with $200 \mu \mathrm{g}$ regimen (fever in $70 \%$ and $24.3 \%, \mathrm{p}<0.001$ ). Brouns et $\mathrm{al}^{9}$ using misoprostol $200 \mu \mathrm{g}$ and $400 \mu \mathrm{g}$ four hourly found success rates of $66 \%$ and $73 \%$ with induction abortion interval of 
11.6 and 9.3 hours respectively $(p=0.04)$ with no significant difference in side effects and $\mathrm{Ho}^{10}$ found $400 \mu \mathrm{g}$ and $200 \mu \mathrm{g} 3$ hourly regimens very effective with success rates of $92 \%$ and $90 \%$ with induction abortion interval of 11.8 and 14.8 hours.

Loading dose studies conducted by Yazdani et al (2012) ${ }^{11}$ found $85 \%$ success rates, Bartley et al (2002),12 Hamoda et $\mathrm{al}(2005)^{13}$ and Hou et al (2010) ${ }^{14}$ found success rates of 94$100 \%$, but with higher side effects i.e. hot flushes, vomiting, diarrhoea, pain, fever, chills. Mean induction abortion interval varied from 4.9 hours in a study by Chai et al,15 $6.2 \mathrm{hrs}$. in Hou's ${ }^{14}$ study, 6.1 hrs. in Bartley's study, ${ }^{12} 6.9$ hours in a study by Websters. ${ }^{16}$ Dickinson et $\mathrm{al}^{17}$ found induction abortion interval of $9.5 \mathrm{~h}$ with oral misoprostol, $7.8 \mathrm{~h}$ with sublingual and $7.4 \mathrm{~h}$ with vaginal but with failure rates of $37 \%$ with oral, $20.5 \%$ with vaginal, $21 \%$ with sublingual.

Considering the literature reviews, regimens with and without LD seems to be not very different in success rates, although it results in slight decrease in induction to abortion intervals. Side effects in LD regimens appear to be higher. A balance needs to be established between side effects, efficacy and induction to abortion intervals. In India where the government is proposing expanding abortion provision by nurses, auxiliary nurse-midwives and practitioners trained in the Indian System of Medicine with recognised qualifications in Ayurveda, Unani, Siddha or homeopathy. It is extremely important to use safer regimens even at the cost of little more time.

\section{CONCLUSION}

We thus conclude that lowering the dose of misoprost from $400 \mathrm{mcg}$ to $200 \mathrm{mcg}$ does not significantly alter the efficacy of the regimen and causes lesser side effects. Also the induction abortion interval is not different. The safety and acceptability will be better in a low resource setting where trained, round the clock facility might not be available.

\section{ACKNOWLEDGEMENTS}

We are indebted to all the residents, nursing staffs and to all the patients for their kind cooperation. We also thank all the obstetricians who helped us in the study with great zeal.

\section{REFERENCES}

[1] Stillman M, Frost JJ, Singh S, et al. Abortion in India: a literature review. New York: Guttmacher Institute, 2014. https://www.guttmacher.org/report/abortionindia-literature-review.

[2] Government of India. Ministry of Health \& Family Welfare. The medical termination of pregnancy (Amendment) Act, 2002.

[3] Wildschut H, Both MI, Medema S, et al. Medical methods for mid-trimester termination of pregnancy. Cochrane Database Syst Rev 2011;(1):CD005216.

[4] American College of Obstetricians and Gynecologists (ACOG). ACOG Practice Bulletin no. 135: Secondtrimester abortion. Obstet Gynecol 2013;121(6):1394406.
[5] RCOG. Best practice in comprehensive abortion care Best Practice Paper No. 2. 2015.

[6] WHO. Safe abortion: technical and policy guidance for health systems. 2nd edn. Geneva: World Health Organization, 2012.

[7] Pongsatha S, Tongsong T. Randomized controlled trial comparing efficacy between a vaginal misoprostol loading and non-loading dose regimen for secondtrimester pregnancy termination. J Obstet Gynaecol Res 2014;40(1):155-60.

[8] Koh SCD, Ang EPJ, Lim SL, et al. A randomised controlled trial comparing two intravaginal misoprostol regimens and gemeprost for midtrimester termination of pregnancy. BJOG 2015:122.

[9] Brouns JF, van Wely M, Burger MP, et al. Comparison of two dose regimens of misoprostol for secondtrimester pregnancy termination. Contraception 2010;82(3):266-75.

[10] Ho PC, Ngai SW, Liu KL, et al. Vaginal misoprostol compared with oral misoprostol in termination of second-trimester pregnancy. Obstet Gynecol 1997;90(5):735-8.

[11] Yazdani SH, Zeinalzadeh M, Bouzari Z, et al. Effects of vaginal versus oral misoprostol to terminate secondtrimester pregnancy. Clin Exp Obstet Gynecol 2012;39(4):529-31.

[12] Bartley J, Baird DT. A randomized study of misoprostol and gemeprost in combination with mifepristone for induction of abortion in second trimester of pregnancy. Br J Obstet Gynaecol 2002;109(11):1290-4.

[13] Hamoda H, Ashok PW, Flett GMM, et al. A randomised trial of mifepristone in combination with misoprostol administered sublingually or vaginally for medical abortion at 13-20 weeks gestation. Hum Reprod 2005;20(8):2348-54.

[14] Hou SP, Fang AH, Chen QF, et al. Termination of second-trimester pregnancy by mifepristone combined with misoprostol versus intra-amniotic injection of ethacridine lactate (Rivanol®): a systematic review of Chinese trials. Contraception 2011;84(3):214-23.

[15] Chai J, Tang OS, Hong QQ, et al. A randomized trial to compare two dosing intervals of misoprostol following mifepristone administration in second trimester medical abortion. Hum Reprod 2009;24(2):320-4.

[16] Webster D, Penney GC, Templeton A. A comparison of 600 and $200 \mathrm{mg}$ mifepristone prior to second trimester abortion with the prostaglandin misoprostol. Br J Obstet Gynaecol 1996;103(7):706-9.

[17] Dickinson JE, Jennings BG, Doherty DA. Mifepristone and oral, vaginal or sublingual misoprostol for secondtrimester abortion: a randomized controlled trial. Obstet Gynecol 2014;123(6):1162-8. 